\title{
Corporate and supply chain network governance of third party logistics service providers: Effects on buyers' intention to continue the relationship
}

\author{
Avci SALIH BÖRTEÇINE \\ Ataturk University Faculty of Economics and Administrative Sciences, Erzurum, Turkey \\ savci@atauni.edu.tr \\ İyigün İSMAİL \\ Trakya University Edirne Social Science Vocational School, Edirne, Turkey
}

\begin{abstract}
This study focuses on the impact of corporate governance, supply chain network governance and competencies such as sales and logistics competence on buyers' intention to relationship continuity. A total number of 258 questionnaires were distributed to Turkish manufacturing firms, selected using cross-sectional sampling method from the Istanbul and Edirne Chamber of Commerce and Industry in Turkey. The data of survey was analysed using PLS-SEM model with WARP PLS 5.0 software. Our findings indicate that corporate governance and supply chain network governance seem to have a positive effect on sales competence and logistics competence, and together, they influence buyers' intention to relationship continuity. In this respect, the outcomes of this study may provide valuable insights for the third-party logistics (3PL) literature in terms of buyers' intention to relationship continuity.
\end{abstract}

Keywords: corporate governance, supply chain network governance, sales competence, logistics competence, continuity of relationship, PLS-SEM.

Please cite the article as follows: Salih Börteçine, A. and Ismail, I. (2017), "Corporate and supply chain network governance of third party logistics service providers: the effects on buyers' intention to relationship continuity", Management \& Marketing. Challenges for the Knowledge Society, Vol. 12, No. 2, pp. 277-296. DOI: 10.1515/mmcks-2017-0017.

\section{Introduction}

Researches in the field of inter-organizational relationships are rich with results which indicate the benefits of long-term cooperation (Anderson and Weitz, 1992; Ganesan, 1994; Cannon et al., 2010). Creating a proper corporate governance (CG) infrastructure has a vital importance for developing long-term cooperation between the parties which constitute the supply chain (Fawcett and Magnan, 2002). CG infrastructure provides the institutions with competence and a strong organizational capability which help improve the cooperation process between organizations (Fawcett et al., 2006). The interorganizational CG which makes significant contributions to the cooperation and partnership issues in the supply chain has become a multi-dimensional phenomenon covering all parties from starting of the ongoing relationships between the parties to their classification and limitation (Heide, 1994; Jain and Dubey, 2005). The objective of inter-organizational CG is to decrease uncertainty, conflict and opportunism (Jain and Dubey, 2005). Thanks to CG which constitutes the relational component of strategic governance, organizations are able to achieve their desired levels of relational competencies in developing the intercompany relationships (Dyer and Singh, 1998), sustainability of collaborative advantages and continuance of competitive of advantages (Barney, 1991).

Besides corporate governance, the governance in supply chain network (SCNG) has a significant importance for the continuance of inter-organizational relationships in 
the supply chain management. SCNG refers to the cooperation process which enables the players who try to do business inside a specific network to work together with a team spirit in the direction of integrated objects (Dyer, 2000). In order to achieve synchronization with all members of the supply chain, the network of relationships has the be continuously kept active. Thanks to that, an opportunity arises for the main company to develop its organizational capabilities such as sale competence and logistic competence.

The level of corporate competencies is significant in inter-company relationships. In this regard, the pressure of competing companies creates challenging aspects in the direction that the suppliers may be able to reveal competencies at competitive level. CG and SCNG which are created in the form of allowing for strengthening the corporate competencies will provide support in resolving the problems and meeting the customer expectations faster (Fawcett et al., 2006; Halldorsson and Larsen, 2004). Governance is important as a mechanism for intercompany relations regulation (Fawcett et al., 2006) and confidence building (Bandsuch et al., 2008) which makes it important for achieving the effectiveness and efficiency of the logistic and sales competence especially in the supply chain. In this regard, CG will take the role of increasing the confidence by strengthening intercompany relationships and will create the infrastructure for strengthening the logistic and sales competence and, in the end, establishing long-term relationships.

In this paper, the effects of CG and SCNG on the basic competencies and long-term relationships through the inter-organizational relationships were reviewed. Especially, we tested what effect CG and SCNG create on sales and logistic competences which have strategic advantages for the parties in the supply chain, and their contributions to maintaining inter-organizational relationships were also assessed. Additionally, we expanded the analysis unit concerning current CG literature. The next parts of this article are organized as follows: firstly, a theoretical explanation is made within the frame of conceptual model created and research hypothesis are explained; then the research methodology and hypotheses tests and empirical results are presented; finally, we provide an ample discussion of the findings and present the limitations of the current research in order to end with suggestions for future investigations.

\section{Theoretical framework and hypotheses}

\section{Corporate governance and governance in supply chain network}

The increase of the significance of strategic cooperation between the partners of supply chain (Paulraj et al., 2007) has made the subject of corporate governance which creates sustainable strategic advantages one of the main topics of discussion in the supply chain literature. Corporate governance which takes the stakeholders of the enterprise and the strategic organizational objectives from a wide perspective (Lui, 2012) is a significant step for market confidence and long-term investments (Pintea, 2015). As the corporate governance is a warranty for the sustainability of the enterprise, several issues have to be addressed: the composition of the management boards in the enterprises, the decision-making process, the information required and the strategy of information management, the shareholders and stakeholders required to be get in contact and required to be in contact. In various countries, the application of corporate governance has become an economic and dynamic way to develop the company's performance and a confirmation of quality which will direct competitive success (Pintea, 2015).

The corporate governance which explained with the help of different theories is taken into consideration with the dimensions of contract governance, interactional 
governance, relational governance and network governance in the supply chain. Contract governance is based on the agency theory which accepts the existence of two parties as the company and the supplier. This viewpoint suggests using the contract in order to warrant that the parties work in the direction of their objectives. The governance system here is shaped in accordance with the contract, power types, incentives and control contract. Relational governance is based on the management theory and resource dependence theory. From this perspective, a governance mechanism which is motivated by organizational objectives is jointly created based on the integration of the individual objectives of the parties which create the supply chain. In this case, cooperation, integration and confidence come to the forefront as the key aspects (Dolci and Maçada, 2014). Governance in supply chain network is defined as the value chain formed by the cooperation process which enables the parties of the supply chain with team spirit created with integrated objectives (Dyer, 2000). These network structures create the most significant multi-organizational governance type (Provan and Kenis, 2007).

There are two types of networks in the supply chain network such as the dominant network and equal partnership network. In the dominant network, a central company creates the dominant part of the value chain. This dominant company is located within a wide network of the bottom companies and supports the system through its products and services. The Japanese Keiretsu is a good example for the dominant network. On the contrary, in the equal partnership network, activities with equal partnership are established and there is no dominant structure of a single partner in its control. Of course, this does not mean that all partners have equal right to speak. In the equal partnership network, different leading companies may reshape the network in the way that they may take advantage of changing market opportunities. The most important benefit of this network type is that it provides flexibility to adapt to changes in the environment faster than in other types of networks (Verwall and Hesselmans, 2004).

\section{Governance as competence}

Governance plays a significant role in developing intrinsic competencies. The competencies in the logistic system allow for the creation of outputs such as customer estimation, dependence and repurchasing intention and the same time, are effective in the creation of high amounts of market share and stakeholder value. Therefore, it has of critical importance that the logistic and supply chain managers and researchers are able to define the ways in which to develop the skill of logistic service. Logistic competence includes the use of competencies available in the current and new markets during the operation. Here, the qualitative changes which have gained a seat in the current competencies of the company play a significant role (Halldorsson and Larsen, 2004, p. 197).

Recently, corporate governance principles have been increasingly studied. The application of these principles increases the value of companies. The sales competence created with the support of governance provides a significant competitive advantage among the members of the supply chain. Through open, accountable and transparent relationships, the companies may develop value increasing relationships and maintaining these relationships. Thanks to that, the companies may find the opportunity of gaining a serious superiority. Corporate governance creates a skill which positively affects the environmental, economic and social development of companies 
through the application of governance principles and their existence in the market (Pintea, 2015).

According to Williamson (1970), a perfect market exchange which is in conformity with their equals is a governance type. The key feature of market exchange is to match the resource share with the price mechanism (Verwall and Hesselmans, 2004, p. 443). Thanks to governance, there is the opportunity of developing a sales strategy not only based on the opinions of intra-organizational members, but also on those of interorganizational parties.

The relation of governance to logistic service competence may be explained in two ways. Logistic service competencies are developed within the external and internal market oriented governance. The first one is to provide participation of the other supply chain members in the provision of solutions for meeting the expectations and needs of the customers. The second one is to focus on researching the premises of logistic service competence with an internal market oriented approach. Here, the focus is the needs and expectations of employees (Halldorsson and Larsen, 2004, p. 198).

In our world which has become a big market in the context globalization, the aspects of change and development have become significant. In such an environment, that the enterprises may survive, may stand against their competitors and provide competition superiority by adapting to the continuously changing environment (Guzel, 2016 , p. 150). Due to the dynamic structure of the market, these are significant in terms of obtaining competitive advantages allowing companies to adapt to fast and unexpected changes and to have a wide support in the field. In the companies which have a high level of logistic competence, it is required to focus on the internal integration strategies as well as integrating the external supply chain (Mollenkopf and Dapiran, 2015, p. 1). Thanks to corporate governance, companies can create the systems to achieve these integration strategies by developing various relationships devoted to the needs of internal and external interest groups.

Governance has a key role in increasing and maintaining the value of relationships established between parties. From this point of view, the exchanging parties may maintain their relationships created by finding the opportunity to develop both their sales and logistic competences and by getting the chance of conducting honest work. In light of these studies, corporate social responsibility, answerability and transparency are accepted as significant dimensions of corporate governance for this study. The dimensions of network governance, long-term focality, information technologies and channel communication are defined as the significant dimensions of governance in supply chain network.

\section{Corporate social responsibility}

Corporate social responsibility (CSR) creates the social side of a sustainable supply chain management (Seuring, 2013). CSR may be defined as the social liabilities for a good corporate citizenship, corporate social investment and interest groups of an enterprise (Porter and Kramer, 2006). CSR may be described as a mechanism which puts forth the liabilities required to be paid attention to in order to follow the policies of institutions and ensuring that the decision and actions of the companies protect the values and objectives of the community (Bowen, 1953).

Although the participation of supply chain members to CSR activities is slow, the significance of CSR in the supply chain has been increasing. Moreover, the responsibilities of supply chain partners devoted to the products become visible not only in relation to the liabilities devoted to CSR activities, but also to those related to the 
sales and delivery periods (Cruz, 2009). There is a need for CSR applications (Friedman, 1970) in order to create an increasing profitability in the service and production by playing in accordance with the rules of the game in an open and transparent way without deception and fraud among the members of the supply chain.

Basically, CSR consists of four dimensions such as economic, legal, ethic and volunteerism. Besides that, the liabilities against the public, the dependency to the conflict group, increase of life quality, economic development, ethical work applications, unchangeable laws, volunteerism, human resources, protection of environment, transparency, accountability (Rahman, 2011) are within the scope of CSR. The competencies are the determinative component for the future tendency of enterprises and therefore, corporate CSR is a significant tool for developing the competencies within the frame of CSR (Schmeltz, 2014). Based on these explanations we will test the following hypotheses:

H1a: CSR is positively associated with sales competence.

H2a: CSR is positively associated with logistics competence.

\section{Accountability}

Accountability is basically related to the fulfillment the liabilities against all parties who are in mutual cooperation. Accountability is a complicated and multi-dimensional concept which is performed operationally through the relationships between the individuals and organizations (Kaynak and Avci, 2014). Even if it is hard to describe accountability, it is a concept including giving information and accountability against a specific status in accordance with a specific consensus. Accountability is the synonym for responsibility in daily colloquialism. Explaining the reason of an action made may be a legal obligation or a moral virtue (Hendry and Dean, 2002). It is possible to explain accountability in terms of supply chain using six dimensions such as economic, ethic, environmental, legal, contract and information accountability (Kaynak and Avci, 2014).

In the strict sense, economic accountability defines a structure which covers reviewing, assessing and questioning the economic performance of all parties. In the wide sense, economic accountability is defined as a more comprehensive structure including the economic behaviors of responsible parties covering the protection of production policies, sustainable and convenient asset values and the conformity of economic and financial aspects to the law and the financial position and reports. The economic conclusions which interest the responsible parties principally question the plan and budget conformity, development of institution and sustainable production skill and the effects of these on the income and welfare of employees by taking the economic performance into consideration (Fa, 1997).

Companies giving account in ethic and social terms happens in a situation in which there are differences not only in regards to the terminology of terms of auditing and reporting, but also of the terms of the method and reporting. It is possible to explain this change by using two main approaches. In the first approach, the companies internally focus on more attractive improvements in ethic issues and there is the requirement at the base of this approach that the companies are required to develop ethic rules and to adhere to the basic ethic principles in relation to all interest groups. Here, it is generally aimed to deepen the values shared in the internal process and shape the individual behaviors, enterprise processes and policies according to these values. In the second approach, it is related to the public, in other words, the external interest groups. In general, this approach is used as linked to public accountability and may be characterized by the development of social report which will be given to the public. 
Here, the basic focal point is to understand the effect on external interest groups. In other words, the first approach is devoted to the "ethic" and the second approach is devoted to the "social" subjects. Both of these create the ethic accountability (Colle and Gonella, 2002).

In the supply chain network, environmental accountability has recently become a very significant subject in terms of enabling the logistic companies in the supply chain network to apply and develop strategies which have environmental responsibility (Goldsbyi and Stank, 2000). The logistic activities which are conducted with environmental responsibility have significant contributions in terms of meeting the customers' needs. Environmental accountability brings the different applications in terms of all logistic services to the forefront of the corporate agenda. The selection of carriers, special carriage of hazardous substances, fuel consumption and decreasing emissions are still priorities in transportation management. Efficiency in environmental issues may be increased by adopting the environmental approaches developed in the green supply chain management and supply chain activities of logistic activities (Guzel and Demirdöğen, 2015). The environmental subjects and the processes such as reverse logistic which are taken into consideration in the green logistic literature have led to a tendency of expanding environmental accountability to all operating processes.

Legal accountability, a concept relevant to the applicability of legal rules, may be defined as a criterion for obeying the legal rules referring to logistic services during the providing the products and services. One side of this work is related to making sure that the mandatory legal controls are regularly conducted. In general, bureaucracy and market expectations are two mechanisms which determine the quality of service. Legal accountability creates a mechanism relevant to the wide scale application of legal conditions which may affect the individual interest of public. Legal accountability is also related to the potential or real existence of political audit and is accepted as an indicator for the good implementation of governance because the state is a significant stakeholder of every institution. Legal accountability has a regulatory role because the institutions create a legal and regulatory environment in terms of procedures and principles along with the parameters which are created by the state within the political and social frame. Laws try to create conscience in order not only to punish the institutions due to their faulty activities, but also in order that they may do the things required for the well-functioning of society. Laws achieve this by focusing on the internal responsibility processes instead of external accountability outputs.

Contract accountability which is an accountability type created according to the contracts previously prepared in the supply chain network focuses on the requirements of system. The creditableness of process is increased with the contracts which are issued in conformity with contract accountability and the existence of some standard aspects such as the contract clauses concerning to parties' responsibilities, the legal basis of contract and performance requirements.

Fundamentally, accountability requires being accountable against the relevant parties in terms of expected performance levels. In this regard, accountability consists of three stages. The first stage is the information stage. This stage is a stage during which information is collected from various sources according to the relevant regulations. The second stage is the discussion stage where discussions and judgments are made in accordance with specific norms and criteria. The third stage is the stage where the sanctions are determined if required and retroactive information is given.

Based on these explanations, the following hypotheses will be tested:

H1b: Accountability is positively associated with sales competence. 
H2b: Accountability is positively associated with logistics competence.

\section{Transparency}

Transparency is a concept which has effect on various aspects such as the procedures agreed on the behalf of establishment of specific relationships, fair sharing, common privileges, long-term association, etc. (Lamming et al., 2001). Transparency which is defined as the process of revealing out the information and unlimited information flow between all relevant parties has a significant place in terms of giving the value expected by the service areas. In terms of the supply chain network, transparency is considered as a process through the ones who receive service may reveal the information at which best alternatives may be tested in order for the public to be enlightened. The existence of a directly proportional correlation between the transparency and confidence (Vaccaro and Madsen, 2009) increases the customer satisfaction level in terms of the ones who receive service and the positive behavior intentions. Transparency is a significant need as it can provide companies with a competitive advantage and with growth and profitability opportunities in the presence of today's changing environmental aspects. The transparency that the logistic companies have created in terms of product and service properties, price, product usability, etc. has a critical place in the continuance of long-term relationships (Vaccaro and Madsen, 2009).

Based on the information acquired from the researches made and from the conceptual frame, below mentioned research hypotheses were suggested with the aim of determining the effect of dimension of transparency and public disclosure on the sales and logistic competence.

H1c: Transparency is positively associated with sales competence

H2c: Transparency is positively associated with logistics competence

\section{Network governance}

The increase of globalization of economic activities and the fast development of information-communication technologies push the enterprises towards creating and developing strategically effective worldwide networks. These networks have focused on finding resource and integrating the production and distribution activities. The supply chain network gives simple and flexible competencies to companies and thanks to that, they may still assume control of the supply (Verwall and Hesselmans, 2004, p. 442).

The advantages of network governance are that it increases learning, makes the resource use more effective, develops the planning capacity by making the resolution of complicated problems easier and makes companies more competitive and allows for offering the best service for the customers (Provan and Kenis, 2007). It may be said in regards to networks, that hierarchy and control purpose governance does not make any sense until the collaborative regulations are created.

Based on these explanations, the below mentioned hypotheses will be tested:

H1d: Network governance is positively associated with sales competence.

H2d: Network governance is positively associated with logistics competence.

\section{Long-term focality}

Long-term focality has the feature of a key factor in sharpening the relational change by maintaining and developing its value during relational change. Long-term focality with the exchanging parties is effective on the rules of conducting honest work such as issuing the contracts which have solidarity, flexibility, mutuality and positive interests, etc. (Paulraj et al., 2007, p. 3). 
The supply chain shareholders inclined towards an understanding based on ethical practices including fair game and good will adopt a long-term partnership. Therefore, such a focality allows for the creation of an effective communication system with low transaction costs and information and data exchange through increasing the sales cost by such a strategic cooperation (Paulraj et al., 2007, p. 4).

The supplier performance which has strong effects on the long-term focality for buyer and suppliers has three factors such as confidence of buyer in the supplier, delivery performance etc. (Cannon et al., 2010, p. 507). Long-term focality decreases the incidence of opportunist behaviors and increases reciprocal confidence by taking the flexibility among the shareholders under protection in the way of helping to resolving the adaptation problems in collaborative relationships (Lui, 2012).

Long-term focality is described as the volunteerism in sacrificing short-term gains for achieving long-term benefits in the relationships with the suppliers (Anderson and Weitz 1992). On the other side, long-term focality is defined as the volunteerism of an economic actor who has a long-term relationship with a specific shareholder and it is deemed as beneficial (Ganesan, 1994).

Based on these explanations, the below mentioned hypothesis will be tested:

H1e: Long-term focality is positively associated with sales competence.

H2e: Long-term focality is positively associated with logistics competence.

\section{Information technology}

Researches have revealed that information technologies are a factor which has critical significance in terms of developing the cooperation between the supply chain shareholders and increasing supply chain performance (Subramani, 2004). The use of information technology in the supply chain will allow for establishment of closer relationships. Information technologies will allow for decreasing the transaction cost between the buyer and the supplier and for creating a more relational and collaborative governance structure (Chae et al., 2005, p. 440).

The development and continuous success of a supply chain is directly correlated to the information technology which is used by the companies. The use of IT in the operating activities is a significant structure which affects the dependence between the confidence and chain members in operation of supply chain and developing the cooperation (Dolci and Maçada, 2014, p. 219).

Information technologies have a significant role in creating the changes based on the supply chain behavior as well as the change in the governance. They are used in coordinating the information sharing and activities between the supply chain members (Dolci and Maçada, 2014, p. 220). Thanks to that, the coordination problems of supply chain are decreased (Prajogo and Olhager, 2011). Moreover, information technologies are a tool which increases the logistic competitive skill. In other words, information technologies may be assessed as a competitive advantage if the information is a logistic resource (Closs et al., 1997).

Based on these explanations, the below mentioned hypotheses will be tested:

H1f: Information technology is positively associated with sales competence.

H2f: Information technology is positively associated with logistics competence.

\section{Channel communication}

Today, when global competition has become a reality, market channels have become significant in terms of the effectiveness and efficiency of organizations. Market channels are effective in ensuring the cooperation between the channel members in achieving the 
individual and systemic objectives. Channel communication has a critical significance in achieving the channel objects. The standardization of communication adversely affects performance. Therefore, it is significant in terms of obtaining the best performance that the channel members are able to establish continuously developing communication in accordance with the changing situations without standardizing the communication. Communication strategies have four dimensions: frequency (related to the amount of communication between the channel members), direction (related to the horizontal or vertical direction of communication), method (related to whether it is formal or informal), and content (related to whether the message is direct or indirect) (Larsen et al., 2002).

Based on these explanations, the below mentioned hypotheses will be tested:

H1g: Channel communication is positively associated with sales competence.

H2g: Channel communication is positively associated with logistics competence.

\section{Sales-logistics competencies and intention to maintain the relationship}

Within the scope of logistic and sales competence in the service procurement, the customers demand low price, best quality, lowest delivery period and creditableness. To respond to these pressures, companies arrange partnership programs with the aim of meeting their needs and increasing the effectiveness of production processes. In other words, information and communication technologies offer ideal tools in order to reinforce information sharing and partnerships with the aim of optimizing the production of companies. Some companies develop the collaborative product trade and customer relations management in all values chain by creating developments in the collaborative value chain solutions which integrate the supply chain management (Verwall and Hesselmans, 2004, p. 442).

Based on these explanations, the below mentioned hypotheses will be tested:

H3: Sales competence is positively associated with buyers' intention to relationship continuity.

H4: Logistics competence is positively associated with buyers' intention to relationship continuity.

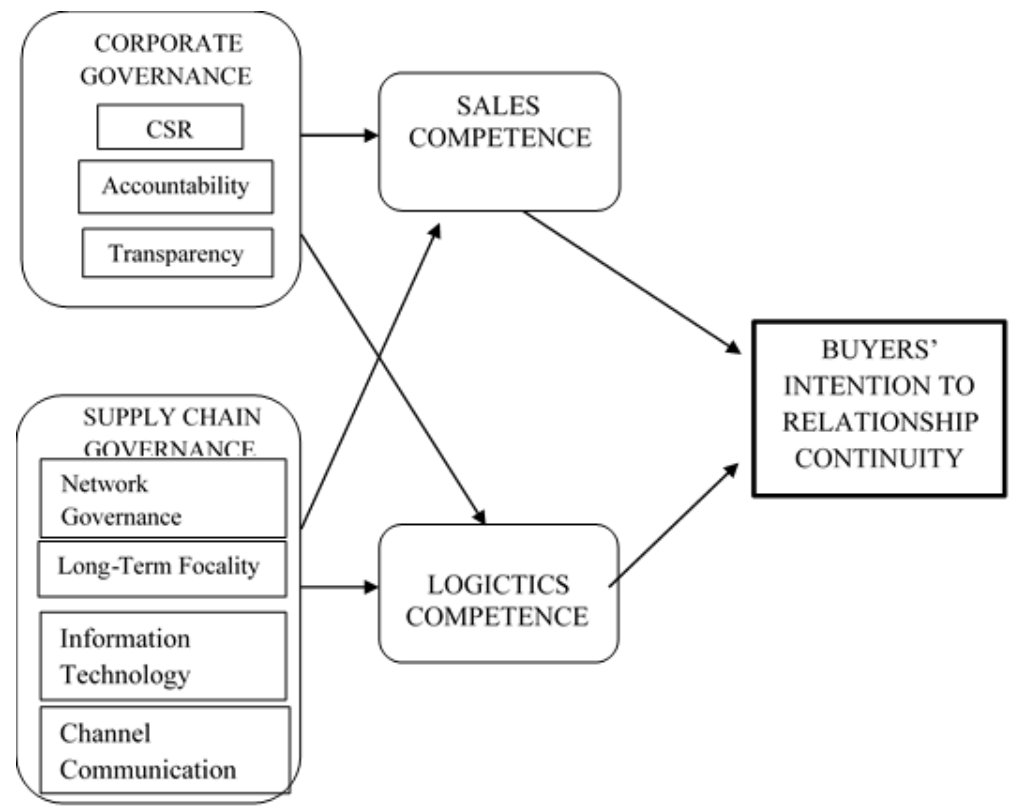

Figure 1. Conceptual model

Source: Authors' own research design. 
The conceptual model seen in Figure 1 reviews the effect of sales and logistic competencies on the intention of the buyer to maintain the relation under the leadership of corporate governance and governance in supply chain network. The model basically reveals the significance of sales competence and logistic competence based on the corporate governance and network governance for the continuity of relationships in the supply chain. In this regard, the model is established on the social relationships of strategic management (Dyer and Singh, 1998).

\section{Research methodology}

\section{Sampling and data collection}

In this paper, the cross-sectional survey method is used in order to collect data. The research is conducted on third party logistic service provider companies and it was requested from their customers to assess the logistic service providers. Accordingly, the companies which perceive the professional logistic enterprises as outsourcing constitute the population of this study. The interviewers were sent to the enterprises which were determined from among the enterprises located in Edirne Chamber of Commerce and Industry and Istanbul European Side and data were acquired as follows.

The frequency distributions and descriptive statistics which are made in order to review the properties of the sample are shown in Table 1 . The participants to the survey mainly consisted of males with ages over 36 and with an educational background of high school or university studies. In regards to the representatives of the companies who responded to the survey, there is a balanced distribution and mid-level managers come to forefront as the position in the company.

Table 1. Profile of the respondents

\begin{tabular}{|c|c|c|c|c|c|}
\hline Gender & Fr. & $\%$ & Department & Fr. & $\%$ \\
\hline Male & 178 & 69 & Purchasing & 28 & 10,9 \\
\hline Female & 75 & 29,1 & Operation & 31 & 12 \\
\hline Total & 253 & 98,1 & Marketing & 49 & 19 \\
\hline Missing & 5 & 1,9 & Logistics/Supply & 46 & 17,8 \\
\hline Total & 258 & 100 & External Trade & 55 & 21,3 \\
\hline Position & Fr. & $\%$ & Other & 36 & 14 \\
\hline Expert & 51 & 19,8 & Missing & 13 & 5 \\
\hline Mid-level mng. & 126 & 48,8 & Total & 258 & 100 \\
\hline Vice President & 9 & 3,5 & Education & Fr. & $\%$ \\
\hline $\begin{array}{l}\text { General } \\
\text { Director }\end{array}$ & 18 & 7 & Primary & 5 & 1,9 \\
\hline Employer & 21 & 8,1 & High School & 49 & 19 \\
\hline Other & 15 & 5,8 & $\begin{array}{l}\text { Vocational } \\
\text { School }\end{array}$ & 89 & 35,5 \\
\hline Missing & 18 & 7 & Graduate & 115 & 44,6 \\
\hline Total & 258 & 100 & Total & 258 & 100 \\
\hline
\end{tabular}

Before the field application, information was given to the interviewers concerning the content of surveys and the issues required to be paid attention to. The data obtained were 279 units. 21 surveys which were determined to be filled casually were eliminated and the number of surveys which could be used in the analyses was 
determined to be 258. The surveys were applied to the mid-level and senior managers of logistic service provider companies who had been performing duty in the departments such as purchasing, production, marketing, logistic/supply chain management, foreign trade, etc. and who had been holding decision maker positions.

The non-response bias was tested in two ways. Primarily, whether there are significant differences in terms of the sampling and main population averaged in the demographic properties; the number of employees and sale volumes were tested by comparison. As a result of the t-test made, it was seen that there is no any statistical difference between the main population and the sample. Besides that, the ones which first and last responses which arrived were compared and support was provided for the non-response bias (Armstrong and Overton, 1977).

\section{Scale development}

The multi-item scale used in this study benefitted from the scales of which reliabilities and validities had been previously tested by other scholars. All items inserted in the scale were prepared in accordance with 5 Likert scale (1: strongly disagree, 5: strongly agree). The corporate governance scale among the scales used in the survey was measured using seven dimensions and consisted of the dimensions of economic, ethic, environmental, legal, contract, informing and transparency (Kaynak and Avcl, 2014). The sales competence scale was developed by the authors. The scale developed by Cannon and Homburg (2001) was used in order to measure the variable of intention of maintaining the relationship. The scale developed by Gattorna et al. (1991) and Chow et al. (1994) was used in order to measure the logistic competence.

The content validity of the scale which was created before collecting data was assessed within the line of current literature. A pre-test was applied before collecting data. The survey questions were primarily reviewed by the experts and academicians in terms of structure, understandability degree, incomprehensibility and integrity of the survey. The final form of the survey was prepared by correcting the incomprehensibilities and the questions which damaged its integrity. The data were controlled before subjecting the analysis and in order to achieve that, the responses given to the question coded in reverse and the parts which were left blank in the survey were primarily reviewed and the normality assumption of data was controlled. In this regard, it was decided that 21 surveys were not convenient for the analysis and they were excluded from the analysis. In the analysis of data, SPSS and WarpPLS5.0 statistic programs were used.

\section{Reliability and validity}

The factor analysis was made for the validity test of scales used in the survey and the Cronbach alpha coefficients were reviewed for the reliability tests. The validity of the scale was tested by using explanatory factor analysis (EFA). The results of these analyses are presented in Table 2. Each indicator in the scales were loaded to its factor as a result of EFA made by using the principal components method. The eigenvalue belonging to these factors is above 1.0 (Hair et al. 1998) and the variance percent is approximately $68 \%$.

In the reliability analysis, the internal consistency was tested by using Cronbach's Alpha method (Cronbach, 1951; Nunally, 1978). When it is reviewed in general, it will be seen that all Cronbach's Alpha values are higher than 0.70 . This result indicates that the conceptual structure is reliable. Alternatively, the reliability of the structure was supported by the composite reliability values suggested by Bagozzi and Yi 
(1988). When these values were reviewed, it was seen that all were higher than 0.70 . From the point of all issues, it may be said that the conceptual structure has good psychometric properties.

Table 2. Factor loadings, scale reliability, AVE

\begin{tabular}{|c|c|c|c|c|c|c|}
\hline Variables & Items & $\begin{array}{l}\text { Factor } \\
\text { Loads }\end{array}$ & $\begin{array}{l}\text { Weight } \\
\text { Indicators }\end{array}$ & $\begin{array}{l}\text { Composite } \\
\text { Reliability }\end{array}$ & $\begin{array}{l}\text { Cronbach's } \\
\text { Alpha }\end{array}$ & AVE \\
\hline \multirow[t]{4}{*}{ CSR } & $\operatorname{csr} 1$ & 0.772 & 0.348 & 0.832 & 0.731 & 0.554 \\
\hline & $\operatorname{csr} 2$ & 0.757 & 0.341 & & & \\
\hline & $\operatorname{csr} 3$ & 0.737 & 0.333 & & & \\
\hline & $\operatorname{csr} 4$ & 0.710 & 0.321 & & & \\
\hline \multirow[t]{6}{*}{ ACC } & ekoacc & 0.735 & 0.194 & 0.911 & 0.883 & 0.632 \\
\hline & etcacc & 0.826 & 0.218 & & & \\
\hline & envacc & 0.805 & 0.212 & & & \\
\hline & lglacc & 0.838 & 0.221 & & & \\
\hline & cntacc & 0.784 & 0.207 & & & \\
\hline & infacc & 0.776 & 0.205 & & & \\
\hline \multirow[t]{4}{*}{ TRS } & $\operatorname{trs} 4$ & 0.869 & 0.295 & 0.918 & 0.880 & 0.736 \\
\hline & $\operatorname{trs} 5$ & 0.848 & 0.288 & & & \\
\hline & $\operatorname{trs} 7$ & 0.872 & 0.296 & & & \\
\hline & $\operatorname{trs} 9$ & 0.843 & 0.286 & & & \\
\hline \multirow[t]{5}{*}{ NTGVR } & ngvr1 & 0.760 & 0.249 & 0.887 & 0.841 & 0.611 \\
\hline & ngvr2 & 0.825 & 0.270 & & & \\
\hline & ngvr3 & 0.790 & 0.258 & & & \\
\hline & ngvr5 & 0.768 & 0.251 & & & \\
\hline & ngvr6 & 0.765 & 0.250 & & & \\
\hline \multirow[t]{4}{*}{ LNGTR } & lgterm1 & 0.850 & 0.325 & 0.883 & 0.822 & 0.654 \\
\hline & lgterm2 & 0.847 & 0.324 & & & \\
\hline & lgterm3 & 0.791 & 0.303 & & & \\
\hline & lgterm4 & 0.741 & 0.283 & & & \\
\hline \multirow[t]{4}{*}{ IT } & it3 & 0.811 & 0.294 & 0.898 & 0.849 & 0.689 \\
\hline & it4 & 0.830 & 0.301 & & & \\
\hline & it5 & 0.863 & 0.313 & & & \\
\hline & it6 & 0.815 & 0.296 & & & \\
\hline \multirow[t]{4}{*}{ NCM } & ncm1 & 0.840 & 0.334 & 0.871 & 0.802 & 0.628 \\
\hline & ncm2 & 0.784 & 0.312 & & & \\
\hline & ncm3 & 0.795 & 0.316 & & & \\
\hline & ncm4 & 0.749 & 0.298 & & & \\
\hline \multirow[t]{6}{*}{ SLCMP } & slcmp1 & 0.793 & 0.177 & 0.947 & 0.932 & 0.748 \\
\hline & slcmp2 & 0.886 & 0.197 & & & \\
\hline & slcmp3 & 0.892 & 0.199 & & & \\
\hline & slcmp4 & 0.908 & 0.202 & & & \\
\hline & slcmp5 & 0.870 & 0.194 & & & \\
\hline & slcmp6 & 0.836 & 0.186 & & & \\
\hline \multirow[t]{2}{*}{ LJCMP } & ljcmp1 & 0.737 & 0.147 & 0.931 & 0.915 & 0.628 \\
\hline & ljcmp2 & 0.763 & 0.152 & & & \\
\hline
\end{tabular}




\begin{tabular}{lllllll}
\hline & ljcmp3 & 0.801 & 0.159 & & & \\
& ljcmp4 & 0.835 & 0.166 & & \\
& ljcmp5 & 0.808 & 0.161 & & \\
ljcmp6 & 0.765 & 0.152 & & \\
MNT & ljcmp7 & 0.804 & 0.160 & & & \\
& ljcmp8 & 0.821 & 0.164 & & & \\
& mnt1 & 0.848 & 0.283 & 0.923 & 0.888 & 0.749 \\
& mnt2 & 0.890 & 0.297 & & & \\
& mnt3 & 0.896 & 0.299 & & & \\
\hline
\end{tabular}

(CSR: Corporate Social Responsibility; ACC: Accountability; TRS: Transparency; NTGVR: Network Governance; LNGTR: Long-Term Focality; IT: Information Technology; NCM: Network Communication; SLCMP: Sales Competence, LJCMP: Logistics Competence; MNT: Buyers' Intention to Relationship Continuity) Notes: Loadings are rotated and cross-loadings are oblique-rotated.

Source: Authors' own research results.

The test result performed with the aim of measuring the correlation level between the variables which create the model was controlled by comparing AVE values (Fornell and Larcker, 1981). According to this test, the correlation value of each variable with each other which create the structure is required to be lower than the AVE value. When the correlation loads given in Table 3 are compared with the AVE values, any correlation value is not higher than the AVE value in the factor structure. These results indicate that there is a strong discriminative validity between all structures in the model. Besides that, it was seen that the discriminative validity was supported through cross loading. In Table 3, it was seen that the factors were in a positive and significant correlation with each other. When the correlation between the factors was reviewed, the highest correlation was determined as 0.687 (between the logistic competence and sales competence) and the lowest correlation was determined as 0.289 (between the information technology and corporate social responsibility factors).

Table 3. Correlations among latent variables

\begin{tabular}{lllllllllll}
\hline & CSR & ACC & TRS & NTGVR & LNGTR & IT & NCM & SLCMP LJCMP & MNT \\
\hline CSR & $\mathbf{0 . 7 4 4}$ & & & & & & & & & \\
ACC & 0.637 & $\mathbf{0 . 7 9 5}$ & & & & & & & & \\
TRS & 0.423 & 0.677 & $\mathbf{0 . 8 5 8}$ & & & & & & & \\
NTGVR & 0.343 & 0.582 & 0.548 & $\mathbf{0 . 7 8 2}$ & & & & & & \\
LNGTR & 0.314 & 0.549 & 0.566 & 0.552 & $\mathbf{0 . 8 0 8}$ & & & & & \\
IT & 0.289 & 0.452 & 0.406 & 0.583 & 0.391 & $\mathbf{0 . 8 3 0}$ & & & & \\
NCM & 0.332 & 0.543 & 0.481 & 0.550 & 0.377 & 0.463 & $\mathbf{0 . 7 9 3}$ & & & \\
SLCMP & 0.321 & 0.562 & 0.538 & 0.602 & 0.439 & 0.362 & 0.513 & $\mathbf{0 . 8 6 5}$ & & \\
LJCMP & 0.442 & 0.666 & 0.586 & 0.545 & 0.509 & 0.451 & 0.557 & 0.687 & $\mathbf{0 . 7 9 2}$ & \\
MNT & 0.469 & 0.580 & 0.513 & 0.527 & 0.508 & 0.307 & 0.481 & 0.640 & 0.676 & $\mathbf{0 . 8 6 6}$ \\
\hline
\end{tabular}

(CSR: Corporate Social Responsibility; ACC: Accountability; TRS: Transparency; NTGVR: Network Governance; LNGTR: Long-Term Focality; IT: Information Technology; NCM: Network Communication; SLCMP: Sales Competence, LJCMP: Logistics Competence; MNT: Buyers' Intention to Relationship Continuity) Note: Square roots of average variances extracted (AVEs) shown on diagonal. 


\section{Structural model and hypotheses testing}

With the aim of testing the model created in this study and acquiring the structural parameters, PLS based structural equation model (PLS-SEM) was used with the help of WarpPLS software (Kock, 2012). When the literature is reviewed, it is seen that the structural equation model (SEM) has an increasing popularity due to the need of testing all theories and structures. The success of various SEM is related to the fact that it may be easily used in assessing the correlations between latent variables. Although the first applications of this method accepted the covariance based structural equation modeling (CB-SEM), certain researchers tend to prefer variance based partial least squares technique (PLS-SEM) (Hair et al., 2014).

PLS-SEM is a technique which provides specific advantages with limited number of responses, abnormal and categorical data. In fact, PLS compares the multi-variable regression and principal components analysis in order to define the dependent variables or latent variables in the models established (Hair et al., 2014).

In this part of study, the correlations between the variables were assessed and it was reviewed whether the hypothesis were confirmed or not. Previously, the correlation analysis was made with the aim of determining the direction and power of the correlations between variables. As significant correlations were seen between the result of correlation analysis and hypothesis established, the causality analyses were made by using the regression analysis. Within this scope, the summary of regression analyses made for the hypothesis and the status of hypothesis are presented in Table 5.

When the information in Table 4 was reviewed, it was accepted that the compliance statistics accepted were within the ideal limits and $p<0.001$. When the values acquired from compliance indexes, it may be said that the scales applied in the sampling and relevant structures were acceptable.

Table 4. Goodness-of-fit indices of the measurement and structural model

\begin{tabular}{|c|c|c|c|c|c|}
\hline & Parameters & Abbr. & $\begin{array}{c}\text { Perfect Fit } \\
\text { Treshold Value }\end{array}$ & $\begin{array}{c}\text { Acceptable } \\
\text { Conformity Length }\end{array}$ & Value \\
\hline \multirow{7}{*}{ 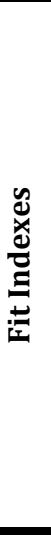 } & AverageBlock VIF & AVIF & Ideally<=3.3 & AcceptableIf $<=5$ & 2.046 \\
\hline & $\begin{array}{l}\text { Average Full } \\
\text { Collinearity VIF }\end{array}$ & AFVIF & Ideally $<=3.3$ & AcceptableIf $<=5$ & 2.273 \\
\hline & TenenhausGoF & GoF & Small $>=0.1$ & $\begin{aligned} \text { Medium }> & =0.25 \\
\text { andLarge }> & =0.36\end{aligned}$ & 0.599 \\
\hline & $\begin{array}{l}\text { Sympson'sParadoxRati } \\
\text { on }\end{array}$ & SPR & Ideally = 1 & AcceptableIf $>=0.7$ & 1.000 \\
\hline & $\begin{array}{l}\text { R- } \\
\text { SquaredContributionR } \\
\text { atio }\end{array}$ & RSCR & Ideally = 1 & AcceptableIf $>=0.9$ & 1.000 \\
\hline & $\begin{array}{l}\text { Statistical } \\
\text { SuppressionRatio }\end{array}$ & SSR & & AcceptableIf $>=0.7$ & 1.000 \\
\hline & $\begin{array}{l}\text { NonlinearBivariateCau } \\
\text { salityDirectionRatio }\end{array}$ & $\begin{array}{c}\text { NLBCD } \\
\text { R }\end{array}$ & & AcceptableIf $>=0.7$ & 1.000 \\
\hline & Sample Size & $\mathbf{N}$ & & \multirow{4}{*}{$\mathrm{P}<0.001$} & 352 \\
\hline & \begin{tabular}{|l|} 
AveragePathCoefficient \\
\end{tabular} & APC & & & 0.172 \\
\hline & Average R-Squared & ARS & & & 0.542 \\
\hline & $\begin{array}{l}\text { AverageAdjusted R- } \\
\text { Squared }\end{array}$ & AARS & & & 0.532 \\
\hline
\end{tabular}

Source: Authors' own research results. 
Table 5. Results of path analysis

\begin{tabular}{|c|c|c|c|}
\hline Paths & Path coefficients & $\begin{array}{c}\mathbf{P} \\
\text { Values }\end{array}$ & $\begin{array}{c}\text { Acceptance } \\
\text { Level }\end{array}$ \\
\hline$C S R \rightarrow S L C M P$ & 0.047 & 0.185 & Rejected \\
\hline$A C C \rightarrow S L C M P$ & 0.224 & $<0.001$ & Accepted \\
\hline$T R S \rightarrow S L C M P$ & 0.122 & 0.010 & Accepted \\
\hline$N T G V R \rightarrow S L C M P$ & 0.333 & $<0.001$ & Accepted \\
\hline$L N G T R \rightarrow S L C M P$ & 0.070 & 0.093 & Rejected \\
\hline$I T \rightarrow S L C M P$ & 0.070 & 0.093 & Rejected \\
\hline$N C M \rightarrow S L C M P$ & 0.174 & $<0.001$ & Accepted \\
\hline$C S R \rightarrow L J C M P$ & 0.037 & 0.243 & Rejected \\
\hline$S C C \rightarrow L J C M P$ & 0.317 & $<0.001$ & Accepted \\
\hline$T R S \rightarrow L J C M P$ & 0.136 & 0.005 & Accepted \\
\hline NTGVR $\rightarrow$ LJCMP & 0.071 & 0.088 & Rejected \\
\hline LNGTR $\rightarrow$ LJCMP & 0.108 & 0.021 & Accepted \\
\hline$I T \rightarrow L J C M P$ & 0.061 & 0.125 & Rejected \\
\hline$N C M \rightarrow L J C M P$ & 0.196 & $<0.001$ & Accepted \\
\hline$S L C M P \rightarrow M N T$ & 0.353 & $<0.001$ & Accepted \\
\hline$L J C M P \rightarrow M N T$ & 0.430 & $<0.001$ & Accepted \\
\hline
\end{tabular}

(CSR: Corporate Social Responsibility; ACC: Accountability; TRS: Transparency; NTGVR: Network Governance; LNGTR: Long-Term Focality; IT: Information Technology; NCM: Network Communication; SLCMP: Sales Competence, LJCMP: Logistics Competence; MNT: Buyers' Intention to Relationship Continuity)

Source: Authors' own research results.

When the findings in Table 5 were reviewed, it was seen that accountability had a strong positive and significant effect on sales competence $(\beta=0.224, p<0.001)$ and logistic competence $(\beta=0.317, p<0.001)$. As a result of the analysis made with the aim of determining the effect of transparency on the sales competence $(\beta=0.122, p=0.010)$ and logistic competence $(\beta=0136, p=0.005)$, it was determined that transparency positively and significant affected these two factors. In terms of the effect of network governance on the sales competence and logistic competence; it was determined that it had no effect on the logistic competence $(\beta=0.071, p=0.088)$ while network governance had a positive significant correlation with the sales competence $(\beta=0.333, p<0.001)$. When the relationships established between long-term focality and competence was analyzed, a positive and significant correlation was determined only on the logistic competence $(\beta=0.108, p=0.021)$ and there was no effect on the sales competence $(\beta=0.070$, $\mathrm{p}=0.093)$. In the analysis made with the aim of assessing the effects of channel communication on sales competence and logistic competence, it was determined that channel communication had a strong positive and significant effect on both sales competence $(\beta=0.174, p<0.001)$ and logistic competence $(\beta=0.196, p<0.001)$. It was determined that sales competence and logistic competence had a strong positive and significant effect on the intention of maintaining the relationship $(\beta=0.353, p<0.001 ; \beta$ $=0.430, \mathrm{p}<0.001)$. As a result of the analyses made, it was concluded that other hypotheses except for these were rejected. 


\section{Findings and discussion}

In the analysis of the intention of maintaining the relationship in 3PL sector, the level of the effect of corporate governance mechanisms of companies and their sales and logistic competence were determined. This has made the study unique because sales and logistic competence have not been previously taken into consideration as important factors affecting the intention of maintaining the relationship. In this study, corporate governance in supply chain networks was determined as a critical factor for qualitatively assessing sales and logistic competences as demonstrated by the empirical testing of the theoretical model developed.

The sub-dimensions were determined in order to explain the effect of corporate governance and governance in supply chain network and the assessment of the effect was explained by analyzing the influence of their sub-dimensions. Accordingly, the subdimensions which create the corporate governance were determined as the corporate social responsibility (CSR), accountability and transparency. It was seen that CSR had no effect on the sales competence and logistic competence. Yet, Schmelt (2014) put forth that CSR is a significant tool in developing these competences. It is thought that the reason for concluding this result which was very interesting in this study was that only CSR studies devoted to the members of supply chain were taken into consideration. It is required to consider this result ordinary when it is assumed that the sales and logistic competence were only collected from the service group devoted to the customers.

It was observed that accountability which is another sub-dimension of corporate governance had a positive and significant effect on both sales competence and logistic competence. Accountability, including the economic, ethic, environmental, legal and contract accountability, has a positive and significant effect on the sales and logistic competence.

As a result of the analyses made we concluded that the dimension of transparency which is the last dimension of corporate governance has a positive and significant effect on both sales competence and logistic competence. The assumption of concerning the fact that transparency provides competitive advantage to the companies in the presence of changing environmental aspects and development and profitability supported our hypothesis.

When we reviewed the effect of network governance, long-term focality and information technologies which are the sub-dimensions of governance in supply chain network were analyzed based on their effects on the competencies. It was determined that network governance had a positive and significant effect on sale competence, but that it had no effect on logistic competence. In this regard, the assumption that the network governance which is established between the shareholders in the supply chain will allow for creating an environment to develop the sales competence was confirmed. It was determined that the dimension of long-term focality has no effect on sales competence, but that it has a positive and significant effect on logistic competence.

It was observed that information technology has no effect on the sales competence and logistic competence. Yet, it was suggested by Closs et al. (1997) that information technologies may significant affect all logistic competences. However, it should be stated that logistic competences depend on whether the logistic activities are fulltime before the integration of information technologies and use-oriented formalization and flexibility (Closs et al., 1997).

It was seen that the channel communication dimension has a positive and significant effect on both sales competence and logistic competence as expected. Indeed, the communication in the supply chain channels has a feature which may be a 
prerequisite in terms of that the sales may reach a specific level and the logistic competence may be used efficiently. Thus, this study revealed that the governance which created the relational appearance of strategic management has a clear contribution to the development of intercompany relationships in the dimension of relational competence (Dyer and Singh, 1998).

In the final part where the effect of sales competence and logistic competence on the intention of maintaining this relationship was analyzed, it was seen that two competencies positively and significantly affected this dimension. In light of this result, the assumption that the effect of governance based sales and logistic competence on the intention of maintaining this relationship was revealed.

\section{Conclusions}

This study provides empirical support for the assumptions that governance affects the sales and logistic competences and that the sales and logistic competences affect the sustainability of the relationship between buyers and suppliers. Today, when the sustainability of the relationships in the supply chain has become a crucial need for increasing the effectiveness and efficiency, sales and logistic competencies are determinants of the will of maintaining the relationship for 3PL companies. It is seen that the quantitative assessments which lie behind these competencies are widely discussed in the literature from different perspectives. But it is clear that these competencies of 3PL companies may not be assessed only with quantitative criteria. There is a need for reviewing the role that qualitative features play in the development of competencies of 3PL companies from different perspectives. Within the scope of this research, the effect of two such qualitative criteria, corporate governance and network governance, on the sales and logistic competencies were reviewed and it is thought that this has made an important contribution to the scientific literature.

The results of this study have showed that it is significant to establish close relationships between the companies from the supply chain perspective. In order to survive and maintain the competitive capacity in the market, organizations have to deal with each other to acquire the desired and necessary sources. There is also a need for intercompany interactions as well as the capacity of supplier in order to provide the necessary information and materials. In fact, the coordination and control between the supply chain members is a governance function. Especially, offering flexible and fast services in the supply chain will be possible with both corporate governance and governance in supply chain network. Within the light of information obtained, the significant role which governance oriented sales and logistic competencies play in maintaining the relationship was confirmed. Governance supported operating competencies have importance in terms of continuance of long-term relationships. Consequently, transparent management processes which consider all interest groups should be created by developing processes and transactions based on informing in order that decision makers and policy makers may establish long-term relationships in the 3PL sector.

The research also has several limitations. Within the bounds of possibility, it was not possible to work with a wider sampling in order to generalize the results. Also, the subject of this study may be expanded with a more comprehensive model in which there are different variables and different company competencies which interest the subject of governance. In future studies, more comprehensive contributions may be provided to the literature by taking these issues into consideration. 


\section{References}

Anderson, E. and Weitz, B.A. (1992), "The use of pledges to build and sustain commitment in distribution channels", Journal of Marketing Research, Vol. 29, No. 1, pp. 18-34.

Armstrong, J.S. and Overton, T.S. (1977), "Estimating nonresponse bias in mail surveys", Journal of Marketing Research, Vol. 14, No. 3, pp. 396-402.

Bandsuch, M., Pate, L. and Thies, J. (2008), "Rebuilding stakeholder trust in business: an examination of principle-centered leadership and organizational transparency in corporate governance", Business and Society Review, Spring, pp. 99-124.

Barney, J. (1991), "Firm resources and sustained competitive advantage", Journal of Management, Vol. 17, No. 1, pp. 99-120.

Bagozzi, R.P. and Yi, Y. (1988), "On the evaluation of structural equation models", Journal of the Academy of Marketing Science, Vol. 16, No. 1, pp. 74-94.

Bowen, H. (1953), Social responsibilities of the businessman, New York: Harper \& Row.

Cannon, J.P. and Homburg, C. (2001), "Buyer supplier relationships and customer firm costs", Journal of Marketing, Vol. 65, No. 1, pp. 29-43.

Cannon, J.P., Doney, P.M., Mullen, M.R. and Petersen, K.J. (2010), "Building long-term orientation in buyer-supplier relationships: The moderating role of culture", Journal of Operations Management, Vol. 28, No. 2, pp. 506-521.

Chae, B., Yen, H.R. and Sheu, C. (2005), "Information technology and supply chain collaboration: moderating effects of existing relationships between partners", IEEE Transactions on Engineering Management, Vol. 52, No. 4.

Chow, G., Heaver, T.D. and Henriksson, L.E. (1994), "Logistic performance: definition and measurement', International Journal of Physical Distribution and Logistics Management, Vol. 24, No. 1, pp. 17-28.

Closs, D.J., Goldsby, T.J. and Clinton, S.R. (1997), "Information technology influences on world class logistics capability", International Journal of Physical Distribution \& Logistics Management, Vol. 27, No. 1, pp. 4-17.

Cronbach, L. (1951), "Coefficient alpha and the internal structure of tests", Psychometrika, Vol. 16, pp. 297-334.

Cruz, J. (2009), "The impact of corporate social responsibility in supply chain management: Multicriteria decision-making approach", Decision Support Systems, Vol. 48, No. 2, pp. 224-236.

Dolci, P.C. and Maçada, A.C.G. (2014), "Information technology investments and supply chain governance", RAC, Vol. 18, No. 2, pp. 217-235.

Dyer, J. (2000), Collaborative advantage: Winning through supply chain network supplier networks, Oxford: Oxford University Press.

Dyer, J.H. and Singh, H. (1998), "The relational view: cooperative strategy and sources of inter-organizational competitive advantage", Academy of Management Review, Vol. 24, No. 4, pp. 660-679.

Fawcett, S.E. and Magnan, G.N. (2002), "The rhetoric and reality of supply chain integration", International Journal of Physical Distribution \& Logistics Management, Vol. 32, No. 5, pp. 339-361.

Fawcett, S.E., Ogden, J.A., Magnan, G.M. and Cooper, M.B. (2006), “Organizational commitment and governance for supply chain success", International Journal of Physical Distribution \& Logistics Management, Vol. 36, No. 1, pp.22-35.

Fornell, C. and Larcker, D.F. (1981), "Evaluating structural equation models with unobservable variables and measurement error", Journal of Marketing Research, Vol. 28, pp. 39-50. 
Friedman, M. (1970), "The social responsibility of business is to increase its profits", New York Times Magazine, September 13th, pp. 32-33.

Ganesan, S. (1994), "Determinants of long-term orientation in buyer-seller relationships", Journal of Marketing, Vol. 58, pp.1-19.

Gattorna, J., Day, A. and Hargreaves, J. (1991), "Effective logistic management", Logistic Information Management, Vol. 4, No. 2, pp. 1-82.

Güzel, D. (2016), Imalatçi KOBİ'lerde Benchmarking Tekniğinin Biliniriliği ve Uygulanabilirliği: Erzurum, Erzincan, Bayburt (TRA1) Bölgesinde Bir Araştırma, Çukurova Üniversitesi İ.I.B.F.Dergisi, Vol. 20, No. 1, pp. 149-161.

Güzel, D. and Demirdöğen, O. (2015), "Yeşil Tedarik Zinciri Yönetimi", The International New Issues In Social Sciences, No. 1, pp. 45-70.

Hair, J.F., Anderson, R.E., Tatham, R.L. and Black, W.C. (1998), Multivariate data analysis, Englewood Cliffs: Prentice Hall.

Hair, J.F., Sarstedt, M., Hopkins, L. and Kuppelwieser, V.G. (2014), "Partial least squares structural equation modeling (PLS-SEM): An emerging tool in business research", European Business Review, Vol. 26, No. 2, pp. 106-121.

Halldorsson, A. and Larsen, T.S. (2004), "Developing logistics competencies through third party logistics relationships", International Journal of Operations \& Production Management, Vol. 24, No. 2, pp. 192-206.

Heide, J. (1994), "Interorganizational governance in marketing channels", Journal of Marketing, Vol. 58, No. 1, pp. 71-85.

Jain, K. and Dubey, A. (2005), "Supply chain collaboration: A governance perspective", Supply Chain Forum - An International Journal, Vol. 6, No. 2, pp. 50-57.

Kaynak, R. and Avci, S.B. (2014), "Logistics service accountabilities and their effects on service buyers' trust", Procedia - Social and Behavioral Sciences, Vol. 111.

Kock, N. (2012), WarpPLS3.0 User Manual, Laredo: ScriptWarpSystems.

Lamming, R.C., Caldwell, N.D., Harrison, D.A. and Phillips, W. (2001), "Transparency in supply relationships: Concept and practice", The Journal of Supply Chain Management, Vol. 37, No. 3, pp. 4-10.

Larsen, T., Rosenbloom, B. and Smith, B. (2002), "Satisfaction with channel communication strategies in high vs. low context culture", Journal of Business to Business Marketing, Vol. 9, No. 1, pp. 1-25.

Lui, S.A. (2012), "Drivers and outcomes of long-term orientation in cooperative relationships", British Journal of Management, Vol. 23, pp. 80-95.

Mollenkopf, D. and Dapiran, G.P. (2015), "The importance of developing logistics competencies: a study of Australian and New Zealand firms", International Journal of Logistics: Research and Applications, Vol. 8, No. 1, pp. 1-14.

Nunally, J. (1978), Psychometric theory, New York: McGraw-Hill.

Paulraj, A., Lado, A.A. and Chen, I. J. (2007), "Inter-organizational communication as a relational competency: Antecedents and performance outcomes in collaborative buyer-supplier relationships", Journal of Operations Management, Vol. 26, pp. 4564.

Pintea, M. (2015), “The relationship between corporate governance and corporate social responsibility", Review of Economic Studies \& Research Virgil Madgearu, Vol. 8, No. 1, pp. 91-108.

Porter, M. and Kramer, M. (2006), "Strategy and society: the link between competitive advantage and corporate social responsibility", Harvard Business Review, Vol. 84, No. 12, pp. 78-92. 
Prajogo, D. and Olhager, J. (2011), "Supply chain integration and performance: The effects of long-term relationships, information technology and sharing, and logistics integration", International Journal of Product Economics, Vol. 135, pp. 514-522.

Provan, K.G. and Kenis, P. (2007), "Modes of network governance: Structure, management and effectiveness", Journal of Public Administration Research and Theory, Vol. 18, pp. 229-252.

Rahman, S. (2011), "Evaluation of definitions: ten dimensions of corporate social responsibility”, World Review of Business Research, Vol. 1, No.1, pp. 166-176.

Schmeltz, L. (2014), "Introducing value-based framing as a strategy for communicating CSR", Social Responsibility Journal, Vol. 10, No. 1 2014, pp. 184-206.

Seuring, S. (2013), "A review of modeling approaches for sustainable supply chain management", Decision Support Systems, Vol. 54, No. 4, pp. 1513-1520.

Subramani, M. (2004), "How do suppliers benefit from IT use in supply chain relationships", MIS Quarterly, Vol. 28 No. 1 pp. 50-75.

Vaccaro, A. and Madsen, P. (2009), "Corporate dynamic transparency: The new ICTdriven ethics", Ethics in Information Technology, Vol. 11, pp. 113-122.

Verwall, E. and Hesselmans, M. (2004), "Drivers of supply network governance: An explorative study of the Dutch chemical industry", European Management Journal, Vol. 22, No. 4 pp. 442-451.

Williamson, O.E. (1979), "Transaction-cost economics: the governance of contractual", Journal of Law and Economics, Vol. 22, No. 2, pp. 233-261. 